\title{
THE UNIVERSITY ELEMENTARY SCHOOL CURRICULUM
}

\author{
FRANK A. MANNY \\ New York City
}

Historically no other elementary-school curriculum has interest for workers in education equal to the one presented by the University Elementary School. There is a convergence here of important streams of influence and one is tempted to look for the results of one and another of the forces that have been at work. Present function and form are however of much more importance than origins, although these latter would necessarily be considered in any thorough study of the former.

The new statement takes advantage of the present concern in industrial education and brings to a focus in this field the various efforts that have been making to socialize the subjects of study and to organize the course from the standpoint of the activities of children and young people who also have relations to the larger social organization. Unity, integration, correlation, inclusiveness, scope are regarded, but one may question whether the principle of differentiation is sufficiently in evidence. In the introduction it is stated that this is the "ultimate end of our curriculum," but there seems to be a division of the field between these two factors, rather than a recognition of their joint activity. This dualism may be as serious in its results as the more common one, which counts habit and drill as the lot of the elementary years, while attention and thinking are reserved for adolescents.

One may wish to defer the trade school until the age of sixteen and appreciate the need of more wisdom than has yet appeared in the use of the elective system in higher schools, without at the same time regarding vocational training as something beyond the elementary period or holding rigidly to one course for all during these years. 
It would be a real service if this problem were more definitely stated. The differentiation of function on the part of children in school as evidenced by a wider range of subjects; specialists as teachers; smaller classes; participation in producing, criticizing, teaching, and governing is certainly an important stage of vocational training and differs from that of later periods more in its experimental character and its lack of fixity than in other features. Again, the relationship of the industrial to the moral deserves clearer definition than is given to it. One feels that the high school, college, commercial interests, and other factors in the larger social situation are regarded too much as outsiders and even as ogres. We have all suffered from the results of their domination, but they are resources which are indispensable in working out the freedom desired.

There is a marked freedom from external domination seen throughout the course. This is refreshing for one turning from the grind of many elementary schools, but on the other hand does this outline consider sufficiently wider relationships? The pupils probably are ready to do good work in the next stage, but one sees little evidence that this problem is taken into account. There are so few institutions in which there is an opportunity for the educational situation to be seen in such wide ranges as at Chicago and Columbia universities that we naturally turn to these for help in understanding the meaning of the large sections with reference to one another-in this case the significance of the elementary school in relation to secondary and higher education.

In the statement, on the whole, the emphasis is upon ideas rather upon execution and administration. The method in a large sense does not appear as a problem-details of subjectmatter and in several cases the work of single grades and especially of departments are projected with considerable clearness but the course as a whole does not build itself up with sufficient coherence out of the excellent studies of social demands and psychological needs that are presented.

It seems ungracious to write thus of a curriculum which marks the latest development of forces which have worked so 
successfully in freeing us from the old schemes in which real needs were choked and smothered by an orderliness so complete that it left little room for activity and life. In one sense statement always lags behind practice and that the course may be of most help to the schools of this country (and those in Europe which I found using the Elementary School Teacher as a valued adviser) there is need that the logical orderly, executive aspect of the school's life, so important in the good work it is accomplishing, should be formulated and communicated rather than be taken for granted. The material is there, and also movement and direction, but organization is lacking. I repeat that it is not domination or fixity that is needed but a projection of an ideal of the whole and an expression of the methods of operation brought to light by this larger forecasting.

It is a pleasure to see how much evidence there is of the results of the work of the children in the making of the curriculum. A school must have an excellent spirit whose course shows so many signs of listening to the pupils and of observing what makes for their growth. There is a minimum of "awakening the minds of the children," of "letting," "restricting," "permitting," etc. In the same way "solving" and "solutions" give way to natural progress. The sentence, "the school grows through study and criticism of its own work," is suggestive, and one of the best expressions of execution is found in connection with the positive function of the museum. But there is limitation in that the "study and criticism" made by pupils, teachers, and departments is not supplemented by that of the secondary school, the college, the outside examiner, and others who must necessarily consider the problem as a whole.

It would be interesting to be told what is the basis upon which omissions of subjects in particular grades are made, also the sequence of subjects in some doubtful cases. There are times when prospective or retrospective reference is assumed beyond the power of the ordinary student to determine it. There is an evident intention to see the past in the light of present needs, but it would be interesting to have a study made of this past material with reference to its justification in each instance 
as to simplicity, etc., and a comparison of the claims of less remote substitutes.

The modern-language announcements are somewhat disappointing. The work seems. advanced for beginners and questions come to mind which a little fuller statement would have cleared up. One feels that some of the sections were written rather for teachers who could fill in details of relationship from direct acquaintance with the work than for those of us who are too far away to have this opportunity. The modern-language work in most elementary schools is in an unsatisfactory condition and institutions which have favorable opportunities have also serious responsibilities. The music department of this school has had a wide influence, but the published course does not seem to do this section justice in several important fields.

Each of the departments invites questions and comment. There is in some of them almost an overwhelming amount of material. One wonders whether this does not signify at times a sacrifice of control to appreciation and whether the attack in many cases could not be more direct and effective and more attention be paid throughout to that factor which in the secondary school we do not hesitate to recognize as scientific.

Despite the apparent tendency of the present critic to emphasize negative features the announcement marks an advance in curriculum-making and gives evidence that the corps behind it is almost ready to give us a whole equal in quality to the best of the parts. 